\title{
Histocompatibility Testing for Organ Transplantation Purposes in Albania: A Single Center Experience
}

\author{
Erkena Shyti ${ }^{1}$, Alma Idrizi ${ }^{2}$, Genc Sulcebe ${ }^{1}$ \\ ${ }^{1}$ Laboratory of Immunology and Histocompatibility, University Hospital Center "Mother Teresa", Tirana, Albania \\ ${ }^{2}$ Department of Nephrology, University Hospital Center "Mother Teresa", Tirana, Albania
}

Background: Histocompatibility testing (HT) which includes donorrecipient human leukocyte antigen (HLA) matching, cross-match testing (XMT) and anti-HLA antibody searching are crucial examinations in solid organ transplantation aiming to avoid the hyperacute graft rejection and also to predict the immunological outcome of the graft.

Aims: The aim of this study was to analyse the tissue typing data collected at the Laboratory of Immunology and Histocompatibility of the University Hospital Center of Tirana, Albania, in order to define those actions that should be taken for improvements in the situation of kidney transplantation in Albania.

Study Design: Descriptive study.

Methods: The donor/recipient cross-match testing was performed through a standard complement-dependent cytotoxicity (CDC) assay using separated donor T and B cells that were tested in parallel with the recipient serum sample. All recipient sera were screened for antiClass I and anti-Class II HLA antibodies using a bead based Luminex anti-HLA antibody screening test. In the case of detected positivity, an allele-specific anti-HLA antibody determination was conducted with the respective Luminex anti-Class I and Class II HLA antibody determination kits.

Results: A total of 174 recipients and 202 donors were typed for the purpose of living donor kidney transplantation at our laboratory between January 2006 and December 2012. The mean age and female gender proportion of patients were 34.9 years and $34.5 \%$, respectively, and 48.0 years and $65.3 \%$ for the donors, respectively. Here, $25.9 \%$ of the patients reported a positive complement-dependent cytotoxicity cross-match test and/or a positive anti-HLA antibody testing result. Eighteen patients that were negative for the complementdependent cytotoxicity cross-match test were positive for anti-HLA antibodies.

Conclusion: The predominant causes of end-stage renal disease (ESRD) in our patient population are chronic pyelonephritis and glomerulonephritis. The female gender is significantly more frequent among donors, which emphasises the need for more gender equity as far as the altruistic willingness for organ donation is concerned. The significant number of patients with Luminex anti-HLA antibody positivity combined with complement-dependent cytotoxicity crossmatch negative results underlines the necessity of using additional methods like cell-based flow cytometry or bead-based Luminex antiHLA antibody assays for the detection of anti-donor-specific antibodies. We also suggest that the number of kidney transplantations in Albania needs to be increased significantly by expanding it with paired exchange living donation and also by implementing an efficient deceased donor kidney transplantation program.

(Balkan Med J 2014;31:121-5).

Key Words: Albanian population, end-stage renal disease, histocompatibility testing, human leukocyte antigens, kidney transplantation
Histocompatibility testing (HT) plays an important role in determining the degree of human leukocyte antigen (HLA) matching between the solid organ recipients and their donors $(1,2)$. It also includes the donor-recipient cross-match testing (XMT) and anti-HLA antibody searches that are crucial examinations in solid organ transplantation, aiming to avoid hyperacute graft rejection and also to predict the immunological outcome of the graft (3-5).

Histocompatibility testing for solid organ transplantation in Albania began in 2006, when a living donor kidney transplan- tation program was implemented at a national level. Since all of the patients from this country are referred to a single laboratory specialised in HT testing, the data obtained in this centre represent the real situation for kidney transplantation tissue typing in the entire country.

The aim of this study was to analyse the data collected in this national reference centre in order to determine the actions that should be taken for improvements in the situation of kidney transplantation in Albania. 


\section{MATERIAL AND METHODS}

In this study we present the data corresponding to a total of 376 individuals (donors and recipients), which have been typed for the purpose of living donor kidney transplantation at the HT reference centre for Albania between January 2006 and December 2012.

The HLA-A, -B and -DRB1 allele genotyping was performed through a generic 2 digit sequence specific priming (SSP) method (Micro SSP ${ }^{\mathrm{TM}}$ DNA Typing Trays; One Lambda, Inc., Canoga Park, USA). In cases of ambiguity and for confirmation purposes, a second sequence-specific oligonucleotide (SSO) method was carried out. In this case, an SSO reverse line (INNO-LiPA; Innogenetics, Gent, Belgium) or a Luminex-based method (LIFECODES; Tepnel Lifecodes Corporation, Stamford, USA) was used.

\section{Cross-match testing}

The donor/recipient cross-match testing was performed through a standard complement-dependent cytotoxicity (CDC) assay (3). Briefly, donor lymphocytes were isolated and separated into T and B cells (FluoroBeads $\mathrm{T}$ and B isolation reagents, One Lambda Inc., Canoga Park, USA). The serum of the recipient was incubated with fresh donor lymphocytes in Terasaki tray wells. A complement source derived from rabbit serum (One Lambda Inc.) was then added, and after proper incubation, a cell staining solution composed of acridine orange, ethidium bromide, and quenching ink (Fluoroquench, One Lambda Inc.) was added into each tray's well. If donor-specific antibodies were present in the patient sera, they would bind to donor cells and the complement cascade would be activated, resulting in the lysis of lymphocytes. The results (as percentage of dead cells) were read using inverted fluorescence microscopy. Positive reactions were reported in the wells where the number of lysed cells is $20 \%$ or higher, and negative reactions in the wells with $0-20 \%$ cell death. Positive and negative T and B cell reacting control sera were included in each test. The negative control consisted of sera from non-transfused blood donor adult males of the $\mathrm{AB}$ group, whereas the positive control was comprised of pooled sera obtained from highly sensitised patients.

Because of the importance of differentiation between IgG and IgM antibodies, we used dithiothreitol (1,4-Dithio-DL-threitol; SigmaAldrich, St Louis, USA), a reducing agent, to inactivate IgM but not IgG in the cross-match assay (6). A positive CDC-XMT result followed by a negative result after DTT treatment was considered indicative of the presence of IgM antibodies only, whereas a positive cross-match despite DTT treatment was an indication of IgG antibody positivity.

\section{Anti-HLA antibody screening with Luminex technology}

All recipient sera were screened for anti-HLA Class I and Class II antibodies of the IgG isotypes using a Luminex bead-based solid phase immunoassay, according to the manufacturer's instructions (Tepnel Lifecodes Corporation, Stamford, CT, USA). Briefly, an aliquot of the micro-beads coated with purified Class I and/or Class II HLA antigens was allowed to incubate with a small volume of test serum sample. The sensitised beads were then washed to remove unbound antibody. An anti-human IgG antibody conjugated to phycoerythrin was then added. After further incubation, the test sample was analysed on a Life-Match fluoroanalyser using the software Luminex 100 IS v 2.3 for data acquisition and Quicktype for Lifematch as the analysis software. Negative and positive control beads and a negative control sample were used to quality control the tests. The mean fluorescence intensity (MFI) of the testing beads was compared to the MFI of the negative control beads to determine whether the testing bead was positive or negative for bound anti-HLA antibodies.

\section{Statistical analysis}

The Fischer exact test was used for testing the statistical significance of differences between categorical data. The study protocol was approved by the ethics committee of the institution and conformed to the ethical guidelines of the 1975 Helsinki declaration. Written informed consent was obtained from all of the patients and donors participating in this study.

\section{RESULTS}

\section{Patients and donors}

From the 376 individuals typed for the purpose of living donor kidney transplantation during the 7 year period from 2006 to $2012,174(46.3 \%)$ were patients and 202 (53.7\%) donors. The age of patients ranged from 6 to 64 years (mean: 34.87 years, SD: 13.51 years). Of these, $114(65.5 \%)$ were males and $60(34.5 \%)$ females $(\mathrm{p}<0.001)$.

The main aetiological diagnoses of end-stage renal disease (ESRD) of the patients, with the corresponding patient numbers in decreasing order, are shown in Table 1. The age of living donors ranged from 19 to 74 years (mean: 48.05 years, SD: 10.95 years). Of them, $70(34.7 \%)$ were males and 132 $(65.3 \%)$ females $(\mathrm{p}<0.001)$.

There were $161(79.7 \%)$ related donors and 41 (20.3\%) unrelated donors $(\mathrm{p}<0.001)$. The detailed data concerning the related and unrelated donors are shown in Table 2.

\section{Cross-match and anti-HLA antibody testing results}

From all 174 patients tested, 45 (25.9\%) had a positive CDC-XMT and/or positive Luminex anti-HLA antibody testing result. Among the 27 donor/recipient positive CDC-XMT patients, $5(18.5 \%)$ were both $\mathrm{T}$ and $\mathrm{B}$ cell positive and also Luminex anti-HLA Class I and Class II antibody positive. The other 22 patients were only B cell positive. Out of them, 5 patients resulted Luminex anti-HLA Class I and Class II antibody positive, 6 patients were Luminex anti-HLA Class I antibody positive, 2 patients were only anti-HLA Class II antibody positive, and 9 patients showed no positivity with Luminex anti-HLA Class I and Class II antibodies. In these 9 patients, the initial CDC-XMT positivity changed to 
TABLE 1. The causative diagnoses of the 174 ESRD Albanian patients studied

\begin{tabular}{lc}
\hline ESRD causative diagnoses & $\begin{array}{c}\text { Number of patients } \\
(\%)\end{array}$ \\
\hline Chronic pyelonephritis & $88(50.6 \%)$ \\
Chronic glomerulonephritis & $55(31.6 \%)$ \\
Polycystic kidney disease & $12(6.9 \%)$ \\
Reflux nephropathy & $10(5.7 \%)$ \\
Nephroangiosclerosis & $6(3.4 \%)$ \\
Diabetic nephropathy & $2(1.2 \%)$ \\
Congenital malformation (Lipomyelomeningocele) & $1(0.6 \%)$ \\
\hline
\end{tabular}

ESRD: end-stage renal disease

TABLE 2. Detailed data about the related and unrelated living donors of the 174 ESRD Albanian patients studied

\begin{tabular}{lrlr}
\hline \multicolumn{2}{c}{ Related donors $(\mathrm{n}=161)$} & \multicolumn{2}{c}{ Unrelated donors $(\mathrm{n}=41)$} \\
\hline Mothers & $56(34.8 \%)$ & Wives & $27(65.9 \%)$ \\
Fathers & $36(22.4 \%)$ & $\begin{array}{l}\text { Emotional (altruistic) } \\
\text { unrelated donors }\end{array}$ & $11(26.8 \%)$ \\
Sisters & $38(23.6 \%)$ & Husbands & $3(7.3 \%)$ \\
Second degree & $17(10.5 \%)$ & & \\
relatives & $13(8.1 \%)$ & & \\
Brothers & $1(0.6 \%)$ & & \\
Son & &
\end{tabular}

ESRD: end-stage renal disease

TABLE 3. CDC-XMT and Luminex anti-Class I and Class II HLA antibody testing results for the 174 ESRD Albanian patients studied

\begin{tabular}{|c|c|c|c|}
\hline \multirow{3}{*}{$\begin{array}{l}\text { Luminex anti-HLA } \\
\text { antibody results }\end{array}$} & \multirow{2}{*}{\multicolumn{2}{|c|}{$\begin{array}{c}\mathrm{CDC}-\mathrm{XMT} \\
\text { negative } \\
(\mathrm{n}=27)\end{array}$}} & \multirow{3}{*}{$\begin{array}{c}\text { CDC - XMT } \\
\begin{array}{c}\text { positive } \\
(\mathrm{n}=18)\end{array} \\
\text { T and B cell } \\
\text { negative } \\
(\mathrm{T}-/ \mathrm{B}-) \\
(\mathrm{n}=18)\end{array}$} \\
\hline & & & \\
\hline & $\begin{array}{c}\mathrm{T} \text { and } \mathrm{B} \text { cell } \\
\text { positive } \\
(\mathrm{T}+/ \mathrm{B}+) \\
(\mathrm{n}=5)\end{array}$ & $\begin{array}{c}\mathrm{B} \text { cell } \\
\text { positive } \\
(\mathrm{T}-/ \mathrm{B}+) \\
(\mathrm{n}=22)\end{array}$ & \\
\hline $\begin{array}{l}\text { Luminex anti-Class I } \\
\text { HLA antibody positive }\end{array}$ & - & $6(3.4 \%)$ & $13(7.5 \%)$ \\
\hline $\begin{array}{l}\text { Luminex anti-Class II } \\
\text { HLA antibody positive }\end{array}$ & - & $2(1.1 \%)$ & $1(0.6 \%)$ \\
\hline $\begin{array}{l}\text { Luminex anti-Class I and II } \\
\text { HLA antibody positive }\end{array}$ & $5(2.9 \%)$ & $5(2.9 \%)$ & $4(2.3 \%)$ \\
\hline $\begin{array}{l}\text { Luminex anti-Class I and Class II } \\
\text { HLA antibody negative }\end{array}$ & II & $9(5.2 \%)$ & $129(74.1 \%)$ \\
\hline
\end{tabular}

negative after DTT treatment, which suggests that the Luminex anti-HLA antibody negativity could be explained by the presence of only IgM, but not IgG, anti-HLA antibodies in these patients. Only those patients who were CDC-XMT negative underwent kidney transplantation.

Eighteen patients that were positive for anti-HLA antibodies detected by Luminex technology were negative following the CDC-XMT method. From these, 4 were both anti-HLA Class I and II positive, 13 only anti-HLA Class I positive and one patient was positive for only anti-HLA Class II antibodies. The data concerning CDC-XMT and Luminex anti-HLA antibody results for all patients are shown in Table 3 .

At the post-transplantation follow-up of the patients, the six-month and one-year graft survival rates were $96 \%$ and $89 \%$, respectively. No correlation was detected between the graft survival and the degree of HLA matching.

\section{DISCUSSION}

In this paper, we present our single centre data about histocompatibility testing results in kidney transplantation in Albania. The average rate of patients typed for the purpose of kidney transplantation in our centre is around 25 per year, which reflects the actual living donor availability for ESRD patients in Albania. Taking into account the Albanian population, the rate of kidney transplantations in Albania can be estimated at less than 8 per one million population (pmp). In other European countries, variable but higher rates are reported, ranging from 16.2 kidney transplantations pmp in Greece, $39.4 \mathrm{pmp}$ in Turkey, $49.4 \mathrm{pmp}$ in Austria and $51.4 \mathrm{pmp}$ in The Netherlands $(7,8)$.

Living donation constitutes $100 \%$ of kidney transplantations in Albania. Although the number of kidney transplantations from living donors is increasing continuously worldwide, they constitute approximately $20 \%$ of all kidney transplantations in Europe, with a large variation ranging from 13\% in Austria, to $51 \%$ in The Netherlands and $82 \%$ in Turkey (8).

The average age of Albanian ESRD patients undergoing tissue typing in our centre is 35 years old. This is comparable with data for Turkish ESRD patients, where a similar mean age is reported (9), but differs from Western European countries, where the average age of the patients undergoing chronic dialysis is steadily increasing (10). Furthermore, as in Turkish ESRD patients (11), the predominant causative diagnoses in our ESRD patients were chronic pyelonephritis or glomerulonephritis, which is in contrast with Western European or North American countries, where diabetes and hypertension are becoming the leading causes of ESRD (12).

It is interesting to note that while the male gender predominates among the patients, there are significantly more female donors than males. These results are similar to other reports, such as those from Turkish, Italian, Chinese and also North American populations, where comparable female/male ratios are found (11-15). These data emphasise the need for more gender equity as far as the altruistic willingness for organ donation is concerned.

It is known that $\mathrm{ABO}$ blood group compatibility is the most important barrier to be overcome in living donor kidney transplantation, while HLA allele matching has only a relative importance (16). In contrast, the donor/recipient XMT as well as the anti-HLA antibody detection among the recipients play very important roles in the prevention of allograft rejection 
$(5,17,18)$. In this concern, the overall rate of donor/recipient CDC-XMT and/or anti-HLA antibody positivity found in our patients of around $26 \%$ is significantly lower than that reported in the USA, where such positivity has been found to be as high as $40 \%$ (19). This lower sensitisation rate may reflect the younger age of Albanian ESRD patients.

Through the CDC-XMT assay, we have found a significant number of $\mathrm{T}$ cell negative/B cell positive CDC results (59\%), even after DTT treatment. The significance of this B cell positivity is to be considered cautiously and other methods for anti-donor-specific antibodies detection must also be performed in these patients $(20,21)$. Through anti-HLA antibody testing by the Luminex method, we have also detected a significant number of cases which were CDC-XMT negative and Luminex anti- HLA antibody positive. These results highlight the above-mentioned need to use other methods in parallel with CDC-XMT for the detection of anti-donor-specific antibodies. Such methods, like cell-based flow cytometry or bead-based Luminex anti-HLA antibody solid phase assays, have a higher sensitivity than the CDC-XMT assay $(22,23)$. On the other hand, these methods are also able to detect non-complement fixing antibodies that seem to have a different clinical significance when compared with the complement fixing antibodies which are generally detected using the CDC-XMT method (24).

As far as the six-month and one-year graft survival rates are concerned, in our study, we did not find any significant difference between the patients who were Luminex anti-HLA antibody positive and those who were anti-HLA antibody negative before transplantation. Regardless, further studies, with more patients and with a longer follow-up are needed to investigate any clinical correlations between the presence of non-complement fixing anti-HLA antibodies and the living donor graft outcome in more detail.

It is well known that related living kidney donation alone is unable to meet the need for kidney transplantation. Therefore, it is clear that the number of kidney transplantations in Albania must be increased significantly by expanding this with non-related paired exchange living donation, and also by implementing an efficient deceased donor kidney transplantation program.

Ethics Committee Approval: Ethics committee approval was received for this study from the ethics committee of the Faculty of Medicine of Tirana University.

Informed Consent: Written informed consent was obtained from patients who participated in this study.

Peer-review: Externally peer-reviewed.

Author contributions: Concept - E.SH., A.I., G.S.; Design - E.SH., A.I., G.S.; Supervision - E.SH., A.I., G. S.; Resourse - E.SH., A.I., G.S.; Materials - E.SH., A.I., G.S.; Data Collection\&/or Processing - E.SH., A.I., G.S.; Analysis\&/or Interpretation - E.SH., A.I., G. S.; Literature Search - E.SH., A.I., G.S.; Writing - E.SH., A.I., G.S.; Critical Reviews - E.SH., A.I., G.S.
Conflict of Interest: No conflict of interest was declared by the authors.

Financial Disclosure: The authors declared that this study has received no financial support.

\section{REFERENCES}

1. Claas FHJ, Dankers MK, Oudshoorn M, van Rood JJ, Mulder A, Roelen DL, et al. Differential immunogenicity of HLA mismatches in clinical transplantation. Transpl Immunol 2005;14:187-91. [CrossRef]

2. Cecka JM. HLA matching for organ transplantation... Why not? Int $J$ Immunogenet 2010;37:323-7. [CrossRef]

3. Patel R, Terasaki PI. Significance of the positive crossmatch in kidney transplantation. N Engl J Med 1969;280:735-9. [CrossRef]

4. Billen EV, Christiaans MH, van den Berg-Loonen EM. Clinical relevance of Luminex donor-specific crossmatches: data from 165 renal transplants. Tissue Antigens 2009;74:205-12. [CrossRef]

5. Batal I, Zeevi A, Lunz JG III, Aggarwal N, Shapiro R, Randhawa P, et al. Antihuman leukocyte antigen-specific antibody strength determined by complement-dependent or solid-phase assays can predict positive donor-specific crossmatches. Arch Pathol Lab Med 2010;34:1534-40.

6. Khodadadi L, Adib M, Pourazar A. Immunoglobulin Class (IgG, IgM) Determination by Dithiothreitol in Sensitized Kidney Transplant Candidates. Transplant Proc 2006;38:2813-5. [CrossRef]

7. Heemann U, Renders L. State of Living Kidney Donation in Europe. Nephrol Dial Transplant 2012;27:2166-70. [CrossRef]

8. European Commission. Organ donation and transplantation, facts and figures journalist workshop 9 Oct 2012. Available from: URL: http://ec.europa.eu/ health/blood_tissue_organs/docs/ev_20121009_facts_figures.pdf.

9. Franke GH, Yücetin L, Yaman H, Reimer J, Demirbas A. Disease-specific quality of life in Turkish patients after successful kidney transplantation. Transplant Proc 2006;38:457-9. [CrossRef]

10. Knoll GA. Is Kidney Transplantation for Everyone? The Example of the Older Dialysis Patient. Clin J Am Soc Nephrol 2009;4:2040-4. [CrossRef]

11. Gures N, Gurluler E, Berber I, Karayagiz AH, Kemik O, Sumer A, et al. Comparison of the right and left laparoscopic live donor nephrectomies: a clinical case load. Eur Rev Med Pharmacol Sci 2013;17:1389-94.

12. Centers for Disease Control and Prevention (CDC). Prevalence of chronic kidney disease and associated risk factors-United States, 19992004. MMWR Morb Mortal Wkly Rep 2007;56:161-5.

13. Santori G, Barocci S, Fontana I, Bertocchi M, Tagliamacco A, Biticchi $\mathrm{R}$, et al. Kidney transplantation from living donors genetically related or unrelated to the recipients: a single-center analysis. Transplant Proc 2012;44:1892-6. [CrossRef]

14. Liu G, Li X, Liu T, Zhao X, Zhang S, Wang J, et al. Gender disparity of living donor renal transplantation in East China. Clin Transplant 2013;27:98-103. [CrossRef]

15. Zimmerman D, Donnelly S, Miller J, Steward D, Albert SE. Gender Disparity in living renal transplant donation. Am J Kidney Dis 2000;36:534-40. [CrossRef]

16. Lee HS, Kim MS, Kim YS, Joo DJ, Ju MK, Kim SJ, et al. Analysis of transplant outcomes after five or six human leukocyte antigenmismatched living donor kidney transplantation. Transplant Proc 2012;44:273-5. [CrossRef]

17. Colombo MB, Haworth SE, Poli F, Nocco A, Puglisi G, Innocente A, et al. Luminex technology for anti-HLA antibody screening: evaluation of performance and of impact on laboratory routine. Cytometry B Clin Cytom 2007;72:465-71. [CrossRef]

18. Lee PC, Ozawa M, Hung CJ, Lin YJ, Chang SS, Chou TC. Reappraisal of HLA antibody analysis and crossmatching in kidney transplantation. Transplant Proc 2009;41:95-8. [CrossRef] 
19. U.S. Department of Health and Human Services, Health Resources and Services Administration, Healthcare Systems Bureau, Division of Transplantation, Rockville, MD. 2009 Annual Report of the U.S. Organ Procurement and Transplantation Network and the Scientific Registry of Transplant Recipients: Transplant Data 1999-2008. U.S. Department of Health and Human Services; 2009.

20. Hwang HS, Yoon HE, Choi BS, Oh EJ, Kim JI, Moon IS, et al. B-cell Complement dependent cytotoxic crossmatch positivity is an independent risk factor for long-term renal allograft survival. J Korean Med Sci 2011;26:528-33. [CrossRef]

21. Minucci PB, Grimaldi V, Casamassimi A, Cacciatore F, Sommese L, Picascia A, et al. Methodologies for anti-HLA antibody screening in patients awaiting kidney transplant: a comparative study. Exp Clin Transplant 2011;9:381-6.
22. Lindemann M, Nyadu B, Heinemann FM, Kribben A, Paul A, Horn PA, et al. High negative predictive value of an amplified flow cytometry crossmatch before living donor kidney transplantation. Hum Immunol 2010;71:771-6. [CrossRef]

23. Lee PC, Zhu L, Terasaki PI, Everly MJ. HLA-specific antibodies developed in the first year posttransplant are predictive of chronic rejection and renal graft loss. Transplantation 2009;88:568-74. [CrossRef]

24. Yabu JM, Higgins JP, Chen G, Sequeira F, Busque S, Tyan DB. C1qfixing human leukocyte antigen antibodies are specific for predicting transplant glomerulopathy and late graft failure after kidney transplantation. Transplantation 2011;91:342-7. [CrossRef] 